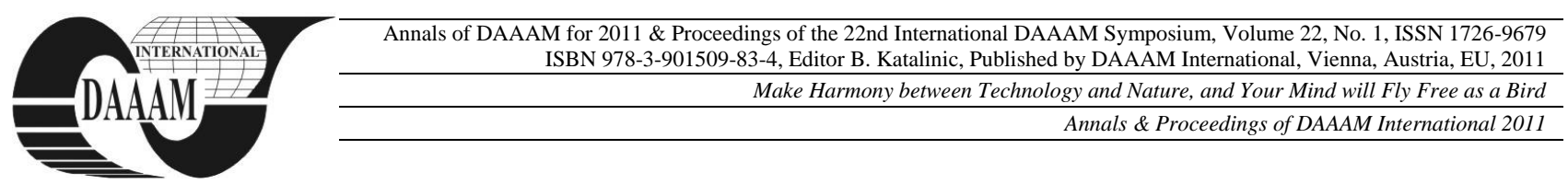

\title{
CREATION PROCESS OF THE INNOVATIVE VIRTUAL ENTERPRISE
}

\author{
PALIKOVA, K[aterina]
}

\begin{abstract}
Intended purpose of this article is to clarify the possibility of a business networking, now mostly represented by virtual enterprises and clusters. Active exploitation of the possibilities offered by a business networking, leads to greater competitiveness of participating companies. The article focuses on virtual enterprises, their creation and functioning so that participating companies are more competitive. The aim of this article is a step by step description of virtual enterprise creation.
\end{abstract}

Key words: effectiveness virtual enterprise, business network, innovation, competitiveness

\section{INTRODUCTION}

Almost every company faces a fight for survival, which usually involves reducing costs, limiting production, reducing employment conditions and sometimes closing down their branches. The greatest potential for the use in this form of business network is offered for small and medium enterprises (SME) which have limited resources, where through involvement in these business networks can help create its own influential market position. Globalization shows that competition is gradually converted to the need for cooperation. The essence of business networking functions is the current impact of two strategies - cooperation in a competitive environment; it is a phenomenon that cannot function without strong leadership and mutual trust. Together they create a positive synergy that will help them create value chain with maximum efficiency. Intended purpose of this article is to clarify the possibility of virtual enterprises.

\section{COMPETITIVE VIRTUAL ENTERPRISE}

Virtual enterprise (VE) has several main features: flexibility, collaboration within the inner group of companies and maximization the values added.

VE is a young concept, so its definition is not entirely settled. There are different interpretations of its meaning, but the fact that it is a temporary network of independent institutions, or specialists is comprehended in all of them. Virtual enterprise comes from Abbe Mowshowitze, who already in the 1980's has developed a "virtual enterprise model." Especially emphasized the essential of temporality, where the company is founded to meet a specific goal and then the company could be dissolved. Thompson (Thompson, 2008) characterizes VE as a temporary alliance of business subjects (company, individual, university etc.) that may perform as mutual competitors. According to Goranson (Goranson, 1999) VE is established in order to exploit business opportunity which could not be exploited individually.

The process of creating an effective value chain of the virtual enterprise, which is composed of selected subjects, is very difficult and is necessary to define a sub-phases. We could define a few basic steps.

- Definition of initiator of the virtual enterprise;
- Analysis of the market potential;

- modeling of the virtual enterprise value chain;

- identification of their own capacity;

- identification of groups of potential cooperating partners;

- creation of virtual enterprise value chain;

- selection of suitable partners for participation in the corporate network;

- creation of an effective medium for sharing data.

\subsection{Initiator - mother company}

Before the emergence of virtual companies it is needed to determine who plays the role of initiator of the VE. The initiator is responsible for the entire value chain creation. This company is the initiator of the contract or business opportunity. Realization is the aim of this VE and the selection and evaluation of potential partners in the business network.

Role of the initiator is for the creation and existence of the VE absolutely crucial. This is a company that is able to exploit business opportunities in the market, but there are several reasons that lead to the necessity of cooperative networks of firms along the value chain.

- The initiator cannot realize the contract in time because don't have enough capacity.

- Initiator doesn't have sufficient resources to realize the contract - hasn't the necessary production equipment, storage facilities, human resources, know-how, or it may require a completely different business focus than he realizes, and many others.

- Initiator is aware that the potential partner has the opportunity to realize some part of the value chain more effectively.

\subsection{Analysis of the market potential}

Initiator identifies market demand for a product, whether there is a market opportunity and whether there is economic interests then it initiate obtaining of the contract. By identification of business opportunity "mother company" will take the role of initiator of the virtual enterprise (Januska, Chodur, 2009). It's necessary to describe all the main requirements of the contract.

- What kind of products are required;

- $\quad$ what quality and quantity is required;

- what is the time interval for realization of the contract;

- what is the technical complexity of the product producing;

- $\quad$ is it necessary to describe all material inputs along parts of value chain;

- what are logistics and transports requirements.

The aim of this modeling is to identify value chain processes of the contract under which is process map created, which is defined and described by M. E. Porter (Porter, 1998). 
The process map helps of successful contract realization. The process map should satisfy two basic conditions:

- chronology of the processes;

- logical continuity of the processes.

\subsection{Identify their own capacity}

The emergence of VEs is being initiated at this stage. The mother company assesses, that doesn't have enough resources to realize the contract in it's own production, or finds out that other business partner can fulfill part of the contract in more effective way than mother company. Selected parts which will be offered to a potential partner emerge from modelling of the value chain processes of the contract.

We can evaluate the effectiveness of the implementation of the value chain by the metrics that are assigned for each part of the value chain. Using these metrics we can select suitable partners for cooperation in the virtual enterprise.

\subsection{The creation of virtual enterprise value chain}

Some processes will be selected based on the analysis of the value chain processes, which will be realized by potential cooperating partner.

- All companies in virtual enterprise have the same objective as the initiator. Realization of the contract which is the reason for the emergence of virtual enterprise.

- During the existence of VE retains the mother company the right to make decisions especially decisions at the strategic level.

- Mother company may also decide about the selection of cooperating subject of business network.

\section{INNOVATION PROCESS IN A VIRTUAL ENTERPRISE}

The innovation in a VE is opportunity especially for SME. These companies have usually limited capabilities and financial resources. Therefore, virtual enterprises create a development center, which are common for member companies. Into what extent they'll move together depends only on the understanding and trust companies themselves and their representatives managers. If a business networking want to innovate own products processes then requires trustworthy and loyal member companies, which together co-operates without any bias, and this relationship is usually for long-term cooperation. Programs for endorsement of innovation could be often seen in terms of vertical virtual enterprise due to its diversity in production activity. For example, the automotive production: one company manufacturing tires, next one plastic, glass, etc. finally a car company builds a new car inside of factory halls. All these companies can work together and discuss how to work more efficiently to bring better value for the customer. It's worse in case of horizontal virtual enterprises, where product range can be in consistent and competitive environment. Programs to support innovation are not excluded here. Innovations are generated by development and innovation centers, purchasing common instruments/devices and technologies, which are then used by all individual companies.

\section{CREATION OF INNOVATION PROCESS}

It is necessary to keep up with following procedure, to obtain the process of innovation across firms in the business networking to be effective.

- First, implementation of the market research - searching for customer's needs. It is no good to ask the customer what he wants to be made, since he is often unable to precisely define or name it. The survey consists of monitoring the needs of his daily work. What is used at the work and how many operations must complete in order to achieve the result, etc. It is also necessary to map out the competition and resources it offers and not to innovate product, which is no longer desirable.

- Then follows by detailed analysis of all collected data from which is possible to determine how it could be done or what action to take to make it easier.

- The next step is to evaluate the analysis and surveys. The output of this phase should be the definition of requirements for improvement.

- Another phase where the whole discussion is an innovative team which is composed of all the relevant disciplines (designers, retailers, technicians from the production preparation, logistics, etc.) and this discussion is to clarify how the problem can be solved. The best method is brainstorming, which has its own strict rules.

- Next point means transforming the acquired information into business ideas and thus creating innovative projects. First are presented proposals of innovative project that are analyzed, and then selected the most appropriate solution.

- Then produced an innovative prototype that is tested, edited and prepared for production.

- To achieve maximum efficiency across the entire value chain it would be desirable for all production inputs to be entered into the criterial function, according to the set of metrics that evaluate the optimal manufacturing process. Therefore, firms involved in the business networking, whether it is a cluster or virtual enterprise should distribute their production activities according to their capabilities and capacities.

\section{CONCLUSIONS}

The life cycles of products are constantly shortened and the customer is increasingly demanding, this article recommends that these virtual enterprises should become innovative. This article also is a procedure that should be followed and the company will benefit from active usage of the potential of business networking activities. In this article I focused on virtual enterprise concept and on the process of its value chain creation. The selection process of potential partners' virtual enterprise value chain was presented. The created process steps of selection serves as a methodological instrument for enhancing the possibility of acquiring a contact and creating a virtual enterprise value chain.

\section{ACKNOWLEDGEMENT}

This paper was supported by the Grant Agency in the Czech Republic (GA CR). Project No. 402/08/H051: Optimizing of multidisciplinary designing and modeling of production system of virtual enterprises.

\section{REFERENCES}

Goranson H. T. (1999). The Agile Virtual Enterprise: Cases, Metrics, Tools, ISBN: 1-56720-264-0, Quorum Books

Januska, M.; Chodur, M. (2009). Virtual Enterprise Network. In ISSE 2009. ISBN: 978-80-214-3874-3, pp. 342-343, Brno University of Technology

Palikova, K. (2010). Roční zpráva - 2010. Available from: http://www.digitov.zcu.cz Accessed: 2010-05

Porter, M. E. (1998). Clusters and the new economics of competition. Harvard Business Review, Vol. 76, Iss. 6, (Nov/Dec 1998), p. 78, ISSN 0017-8012

Thompson, K. (2008). The networked Enterprise, USA, Meghan-Kiffer Press, ISBN 0-929652-45-2 